\title{
International
}

Journal of Thysical

ofducation

DOI : 10.15740/HAS/IJPE/8.1/40-44

e ISSN-0976-7924 Visit us : www.researchjournal.co.in

Research Paper

Volume 8 | Issue 1 | April, 2015 | 40-44

\section{Factor analysis of selected anthropometric and physical variables of elite Indian volleyball players}

\section{NANDKISHOR PAWAR}

Received : 31.12 .2014 ; Revised : 08.03.2015; Accepted : 21.03 .2015

\section{Author for correspondence}

NANDKISHOR PAWAR

Lakshmibai National Institute of

Physical Education, GWALIOR

(M.P.) INDIA

Email: nandkishor1017@yahoo.in

\section{-ABSTRACT}

The purpose of the study was to identifying selected anthropometric and physical variables representing selection criteria of elite Indian volleyball players under through identifying the factorial structure of these variables. For this purpose $(n=104)$ male volleyball players were purposively selected from Senior National volleyball Championship. The age of these subjects ranges from 19 to 33 years. 15 anthropometric parameters were measured namely, Height, Weight, Arm Length, Hand Length, Palm Width, Arm Girth Relax, Arm Girth Flex, Fore Arm Circumference, Wrist Circumference, Chest Circumference, Thigh Circumference, Calf Circumference, Ankle Girth, Leg Length, Foot Length, Foot Width, Speed, Shoulder Strength, Explosive leg Strength, Agility, Flexibility, Abdominal Strength and body Composition. Principal component factor analysis was used for extracting factor scores from the factor, which were adopted as an indicator of the performance capability in volleyball. Findings revealed four extracted factors, according to the content of their respective items, and were named Anthropometric factor, Girth factor, Strength factor and Physical factor.

- KEY WORDS : Factor analysis, Anthropometric and physical variables, Volleyball players

- HOW TO CITE THIS PAPER : Pawar, Nandkishor (2015). Factor analysis of selected anthropometric and physical variables of elite Indian volleyball players. Internat. J. Phy. Edu., 8 (1) : 40-44. 